\title{
THE ROLE OF MAGNETIC RESONANCE IMAGING IN THE DIAGNOSIS OF GYNAECOLOGIC PELVIC TUMOURS
}

\author{
El-Gharib MN; Dawoud MA; Mashally EM and Ahwal HS
}

From Departments of *Obstetrics \& Gynaecology and Radiodiagnosis, Faculty of Medicine, Tanta University, Tanta, Egypt

\section{ABSTRACT}

Objective : To assess the role of magnetic resonance imaging in the diagnosis of gynaecological pelvic tumours.

Design: Prospective study.

Setting : Tanta University Hospitals .

Patients : The study included 49 women diagnosed clinically as having pelvic tumours.

Intervention: All the patients were subjected to history taking, physical examination, transabdominal and/or transvaginal ultrasound, pelvic MRI and pathological examination of the specimens.

Outcome measures: Specificity of MRI in diagnosis of gynecologic pelvic tumours.

Results: We found that the specificity of MRI in the diagnosis of uterine fibromyomata and adenomyosis was $100 \%$. In cases of malignant uterine tumours, we found that MR was the imaging modality of choice in crarly diagnosis and staging of endometrial carcinoma as it exhibits if there is myometrial invasion or not. Ultrasound was false negative in $40 \%$ of endometrial carcinoma. Both ultrasound and MRI were equivocal in diagnosis of benign ovarian lesions, but MRI was superior to ultrasound in diagnosis of benign extraovarian lesions. MRI succeeded in diagnosis of the pathological pattern of benign ovarian lesions and in the discrimination between benign and malignant ovarian tumours. Conclusion: MR imaging is a valuable modality in the evaluation of female pelvic tumours when the sonographic diagnosis is nonspecific.

Key words: MRI, US, female pelvic tumours

\section{INTRODUCTION}

Magnetic resonance (MR) imaging has been a clinical tool for the past 15 years; it has been primarily used for imaging the central nervous and musculoskeletal systems, with applications in body imaging lagging far behind ${ }^{(1)}$.

MR imaging is becoming an increasingly important tool in the diagnosis of benign and malignant disease of the female pelvis. Although ultrasound (US) and hysterosalpingography (HSG) remain the primary forms of imaging, MR imaging is now routinely used in the diagnostic work-up of infertility, including mullerian anomalies, and chronic pelvic pain. Both CT and MR imaging can be used to determine the origin of and to characterize a pelvic mass. Staging of gynecologic malignancies can also be performed with both modalities. In obstetrics, MR imaging is used to assess maternal complications of pregnancy and to identify or confirm fetal anomalies ${ }^{(2)}$.

MR imaging has become a valuable modality in the evaluation of the female pelvis. In many cases, it follows the performance of HSG or US. These cases include infertility and pelvic pain. In some cases, it should serve as the test of choice. This is true in the local staging of cervical cancer and the evaluation of pain or disability in the pregnant patient. Finally, in the evaluation of advanced gynecologic cancers, it is usually a secondary choice with CT preferred ${ }^{(3)}$.

The noninvasive nature of MR imaging is beneficial in evaluations of what are probably benign diseases in 
young women of reproductive age. Although MR imaging is believed to be safe even during pregnancy, a cautious approach that involves waiting until after 12 weeks' gestation is recommended ${ }^{(4)}$.

MR is the diagnostic imaging modality of choice for many disorders of the female pelvis. Benign uterine disease is well-demonstrated using rapid sequences and minimal examination time, whereas evaluaiton of malignancy is best performed with high-resolution techniques ${ }^{(5)}$.

Disadvantages of MR imaging are its high cost and long scanning time. Its excellent tissue contrast underscores its importance in the evaluation of adnexal masses, however, because it allows spécific diagnoses of fat, blood, and fibrous tissue. Even if normal in size, an ovary may present with tiny foci of endometrial implants or dermoid cysts that are only identifiable on MR imaging; however, MR imaging is generally used as a problem-solving modality. When ultrasound results are inconclusive, the use of MR imaging may alter treatment decisions, eliminate the need for surgery, and result in reduced overall costs ${ }^{(5)}$.

The aim of the work is to assess the role of magnetic resonance imaging in the diagnosis of different female pelvic organ lesions.

\section{PATIENTS}

This study included 49 patients; their age ranged from 15 to 65 years. Selected patients were having the following:

- Clinically enlarged uterus.

- Pelvic mass with its nature and origin are equivocal by trans-abdominal ultrasonography (TAS).

- Proved adnexal masses by US for further tissue characterization by MRI.

All patients were referred to the Radiology and Imaging Department, from the Gynecology \& Obstetrics Department, Tanta University Hospitals during the period from June 2003 to June 2007.

\section{METHODS}

All patients were subjected to the following :-

1. History taking and clinical examination.

2. Routine laboratory investigations including complete blood picture, blood sugar, liver and renal function, and Serum CA 125 in patients who had ovarian malignancies.

3. Transabdominal and/or transvaginal US.

4. Pelvic MRI examination which was done for all the patients.

5. Pathological examination of the tumours.

\section{RESULTS}

The age of the studied patients ranged between 15 and 65 years with a mean age of 34.72 years.

The clinical presentations of the patients revealed that chronic pelvic pain was the main presenting symptom in $52.38 \%$; it was the only complaint in $24.44 \%$ and associated with other symptoms in $40.00 \%$ of patients. Pelvic swelling was the main complaint in $46.66 \%$, whereas $28.90 \%$ of patients presented with abnormal uterine bleeding.

\section{DISCUSSION}

The role of MRI in the diagnosis of gynecologic diseases has increased during the last two decades. Many reports indicate that MRI is useful in evaluating the female pelvis, and it has been recommended for further evaluation of ultrasonographically indeterminate pelvic masses. However, there are few published data demonstrating objective evidence that MRI is beneficial after an equivocal US examination ${ }^{(6)}$.

The current study revealed that MRI was very useful in solving problems of the female pelvis that face other methods of investigations, and we found that clear visualization of the anatomic details of the uterus \& ovaries particularly in $\mathrm{T} 2$ weighted images was depicted, and different sequences confidently identify the tissue of origin of deifferent lesions encountered in our study. This helps in the accurate diagnosis which 
Table I: Clinical presentation of patients.

\begin{tabular}{|l|c|c|}
\hline \multicolumn{1}{|c|}{ Presentation } & Number & $\%$ \\
\hline Chronic pelvic pain & 11 & 24.44 \\
\hline Pelvic swelling & 21 & 46.66 \\
\hline Abnormal uterine bleeding & 13 & 28.90 \\
\hline Total number of patients & 45 & $100 \%$ \\
\hline
\end{tabular}

Table II : MRI findings of the different pelvic lesions in the examined patients."

\begin{tabular}{|c|c|c|}
\hline Pathology & No. of patients & $\%$ \\
\hline $\begin{array}{l}\text { Benign uterine lesions } \\
\text { - Fundal interstitial myoma } \\
\text { - anterior uterine wall interstitial \& subserous myomas } \\
\text { - Posterior uterine wall interstitial myoma } \\
\text { - Interstitial posterior uterine wall myoma extending } \\
\text { submucous } \\
\text { - Posterior uterine wall subserous myoma } \\
\text { - Uterine adenomyosis }\end{array}$ & $\begin{array}{l}15 \\
2 \\
3 \\
1 \\
1 \\
2 \\
6\end{array}$ & 30.6 \\
\hline $\begin{array}{l}\text { Malignant uterine lesions } \\
\text { - Endometrial carcinoma } \\
\text { - Leiomyosarcoma } \\
\text { - Malignant endometrial polyp } \\
\text { - Cervical carcinoma } \\
\end{array}$ & $\begin{array}{l}10 \\
5 \\
3 \\
1 \\
1\end{array}$ & 20.4 \\
\hline $\begin{array}{l}\text { Benign ovarian lesions } \\
\text { - Simple ovarian cysts } \\
\text { - Serous cystadenoma } \\
\text { - Mucinous cystadenoma } \\
\text { - Ovarian torsion } \\
\text { - Dermoid cyst } \\
\text { - Endometriotic cyst } \\
\text { - Bilateral PCO } \\
\end{array}$ & $\begin{array}{l}12 \\
3 \\
2 \\
1 \\
1 \\
2 \\
2 \\
1 \\
\end{array}$ & 24.5 \\
\hline $\begin{array}{l}\text { Benign extraovarian lesions } \\
\text { - Para-ovarian cyst } \\
\text { - Broad ligament haematoma }\end{array}$ & $\begin{array}{l}3 \\
2 \\
1\end{array}$ & 6.1 \\
\hline $\begin{array}{l}\text { Malignant ovarian lesions } \\
\text { - Papillary serous cystadenocarcinoma } \\
\text { - Mucinous cyst adenocarcinoma } \\
\text { - Granulosa cell tumor } \\
\end{array}$ & $\begin{array}{l}9 \\
6 \\
2 \\
1\end{array}$ & 18.4 \\
\hline Total & 49 & 100 \\
\hline
\end{tabular}

*These findings were confirmed by the pathological examination, the golden standard. 
Table III: MR intensity pattern of uterine myomas.

\begin{tabular}{|c|c|c|c|c|}
\hline \multirow{2}{*}{ Pathology } & \multirow{2}{*}{ No. } & \multicolumn{3}{|c|}{ MR signal characteristics } \\
\hline & & T1-weighted image & T2-weighted Image & Endometrial line \\
\hline $\begin{array}{l}\text { Fundal uterine } \\
\text { myomas }\end{array}$ & 2 & $\begin{array}{l}\text { Well defined intermediate } \\
\text { signal intensity, one case } \\
\text { showed bright dots } \\
\text { corresponding to Hemorrhage. }\end{array}$ & $\begin{array}{c}\text { Mixed medium } \\
\text { signal intensity with } \\
\text { bright areas }\end{array}$ & $\begin{array}{l}\text { Seen pushed and } \\
\text { compressed } \\
\text { downward }\end{array}$ \\
\hline $\begin{array}{l}\text { Anterior uterine wall } \\
\text { myomas }\end{array}$ & 3 & Hypo intense, Intramural & $\begin{array}{l}\text { Hypo intense with } \\
\text { bright areas } \\
\text { corresponding to } \\
\text { degeneration }\end{array}$ & $\begin{array}{l}\text { Displaced } \\
\text { posteriorly }\end{array}$ \\
\hline $\begin{array}{l}\text { Posterior uterine } \\
\text { myomas }\end{array}$ & 4 & $\begin{array}{l}2 \text { patients were intramural, one } \\
\text { of these intramural extending } \\
\text { submucous showed mixed SI, } \\
\text { and } 2 \text { patients subserous all } \\
\text { displaying hypointense SI }\end{array}$ & $\begin{array}{c}\text { Heterogenous SI } \\
\text { (Hypointense mixed } \\
\text { with bright areas) }\end{array}$ & $\begin{array}{c}\text {-Displaced anteriorly } \\
\text {-Thinned and } \\
\text { displaced anteriorly } \\
\text {-No significant } \\
\text { displacement }\end{array}$ \\
\hline
\end{tabular}

Table IV: MR findings in adenomyosis.

\begin{tabular}{|c|c|c|c|c|c|}
\hline \multirow{2}{*}{ Pathology } & \multirow{2}{*}{$\begin{array}{l}\text { No. of } \\
\text { cases }\end{array}$} & \multicolumn{3}{|c|}{ MR signal characteristics } & \multirow{2}{*}{$\begin{array}{l}\text { Other associated } \\
\text { findings }\end{array}$} \\
\hline & & $\begin{array}{l}\text { T1-weighted } \\
\text { image }\end{array}$ & $\begin{array}{l}\text { T2-weighted } \\
\text { image }\end{array}$ & $\begin{array}{c}\text { Mean Junctional } \\
\text { zone }\end{array}$ & \\
\hline $\begin{array}{l}\text { Focal uterine } \\
\text { adenomyoma }\end{array}$ & 2 & $\begin{array}{c}\text { Well defined } \\
\text { intramyometria! } \\
\text { lesion with bright } \\
\text { signal }\end{array}$ & $\begin{array}{c}\text { Hypointense } \\
\text { centre with } \\
\text { marginal high SI }\end{array}$ & $\begin{array}{l}\text { Normal width } \\
12 \mathrm{~mm}\end{array}$ & $\begin{array}{c}\text { Left ovarian } \\
\text { endometriotic cyst }\end{array}$ \\
\hline $\begin{array}{l}\text { Diffuse uterine } \\
\text { adenomyosis }\end{array}$ & 4 & Hypointense & $\begin{array}{l}\text { Hyperintense foci } \\
\text { and strands in the } \\
\text { myometrium }\end{array}$ & $18 \mathrm{~mm}$ & -- \\
\hline
\end{tabular}

Table V: MR intensity pattern of malignant uterine lesions.

\begin{tabular}{|l|c|c|c|c|}
\hline \multirow{2}{*}{ Pathology } & \multirow{2}{*}{ No. } & \multicolumn{4}{|c|}{ MR signal characteristics } \\
\cline { 3 - 6 } & 6 & T1-weighted image & T2-weighted Image & Additional findings \\
\hline Endometrial carcinoma & 6 & $\begin{array}{c}\text { In homogenous } \\
\text { hyperintense }\end{array}$ & $\begin{array}{c}\text { Myometrial invasion } \\
\text { was seen in three } \\
\text { patients }\end{array}$ \\
\hline $\begin{array}{l}\text { Malignant endometrial } \\
\text { polyp }\end{array}$ & 1 & $\begin{array}{c}\text { Intermediate SI surrounded with } \\
\text { linear bright signal intensity }\end{array}$ & Hypointense & $\begin{array}{c}\text { Multiple metastatic } \\
\text { lymph nodes }\end{array}$ \\
\hline Leiomyosarcoma & 2 & $\begin{array}{c}\text { Heterogenous signal intensity } \\
\text { mixed low with height signal } \\
\text { intensities }\end{array}$ & $\begin{array}{c}\text { Heterogenous } \\
\text { intensity low SI with } \\
\text { bright and medium } \\
\text { SI areas }\end{array}$ & $\begin{array}{c}\text { Endometrial line can } \\
\text { not be distincted in } \\
\text { two cases }\end{array}$ \\
\hline Cervical carcinoma & 1 & Intermediate SI & Intermediate SI & $\begin{array}{c}\text { Infiltrating the } \\
\text { pericervical fat } \\
\text { planes and UB base }\end{array}$ \\
\hline
\end{tabular}



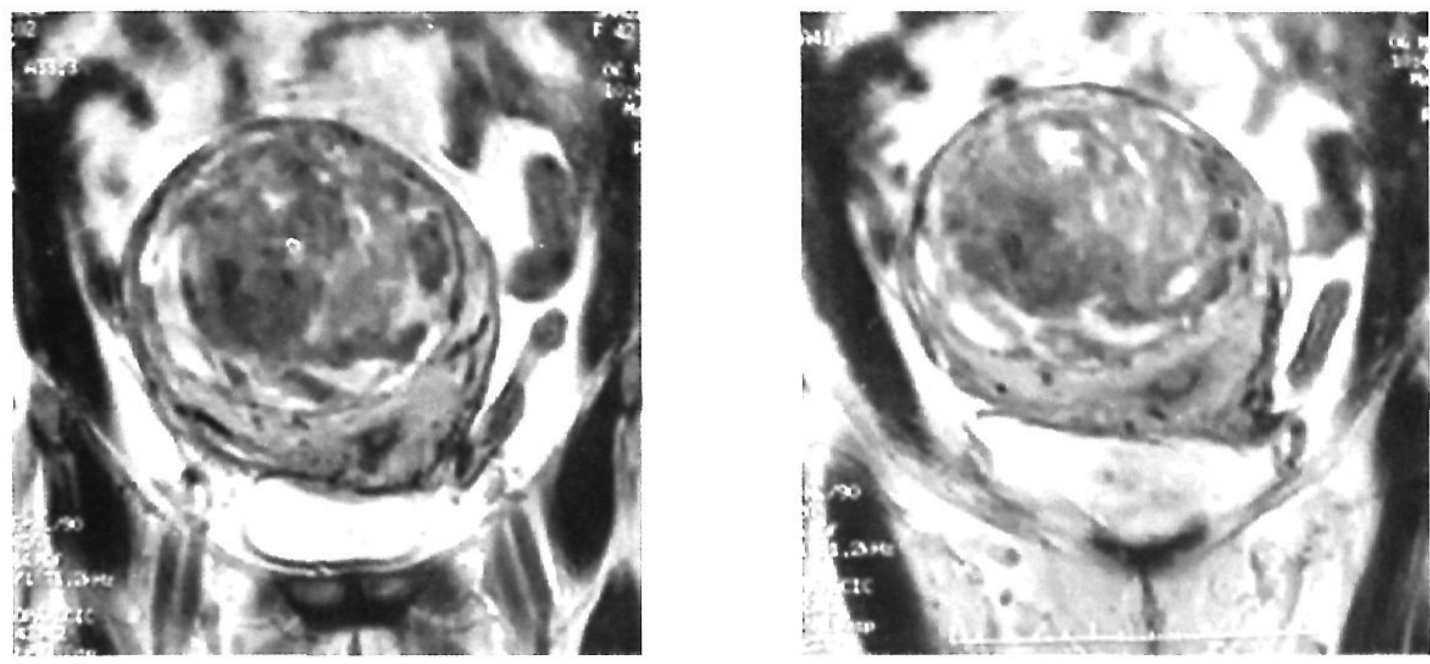

Figure 1. Coronal T2 weighted image showing posterior uterine wall myonil extending submucous, the endometrium lining is pushed to the right side.
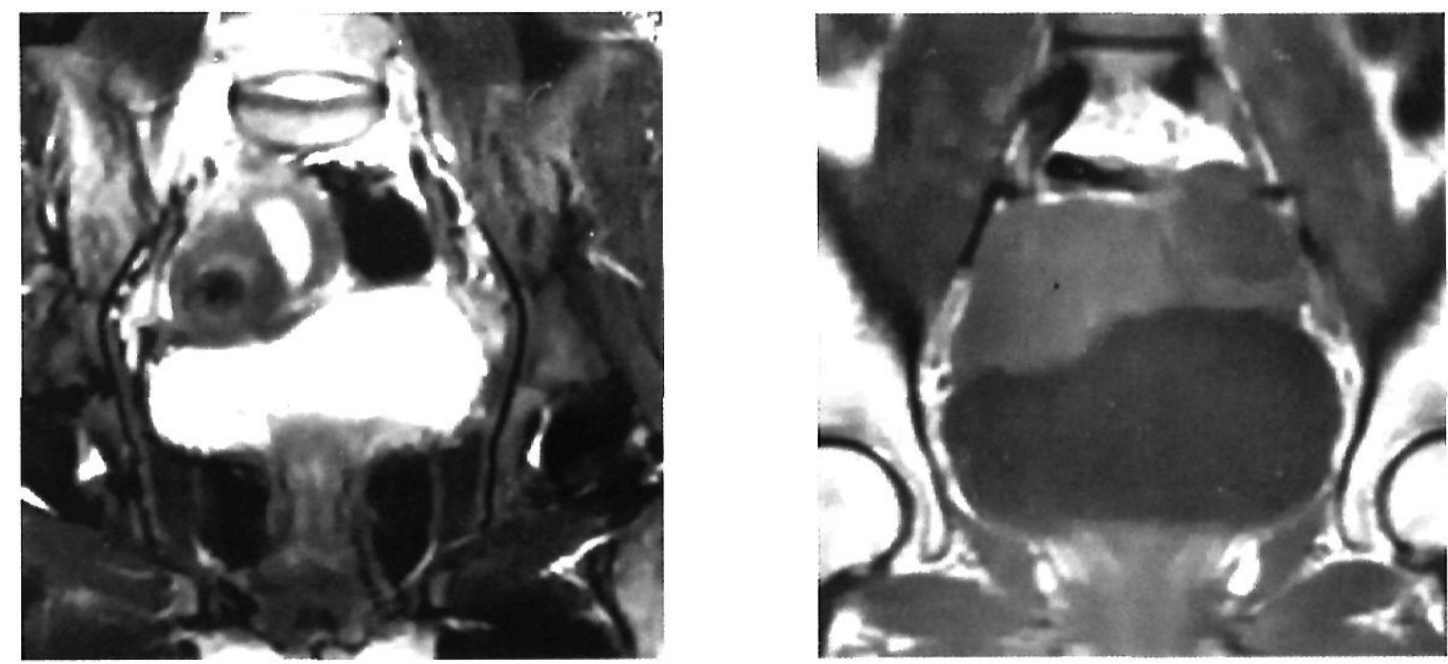

Figure 2. Coronal T2 weighted image showing focal adenomyosis and left ovarian endometrioma.
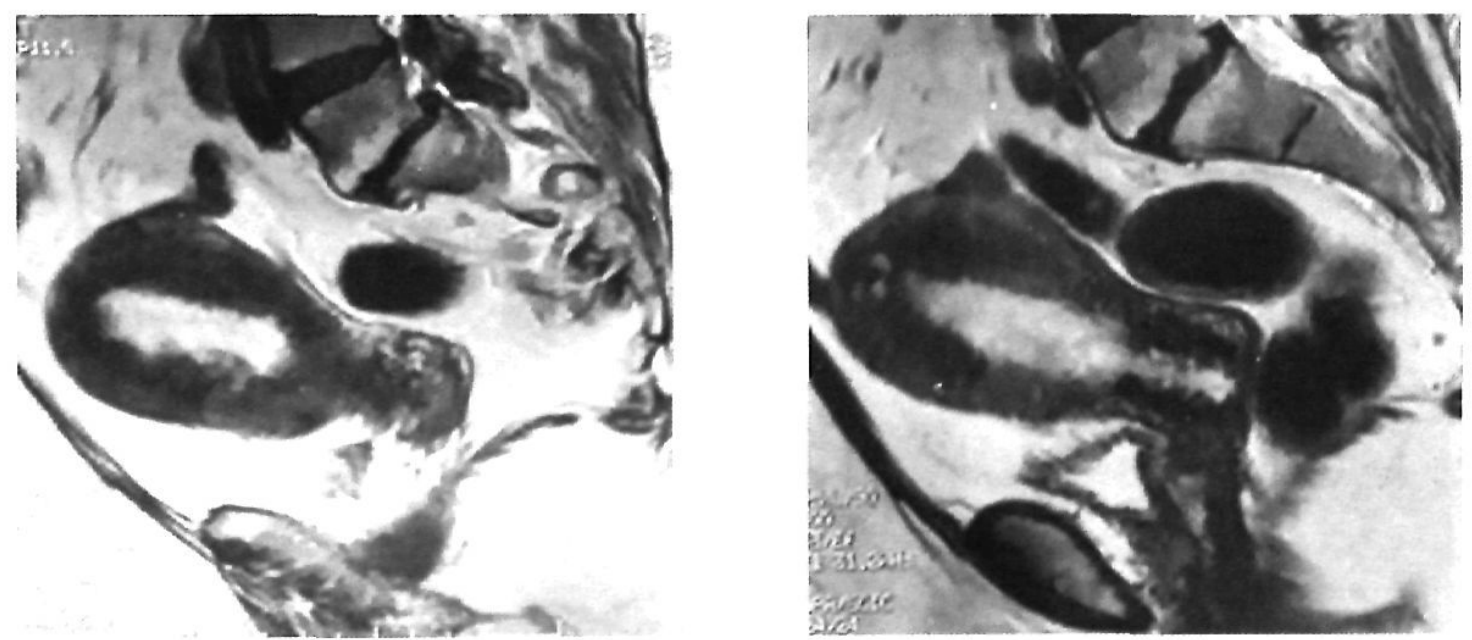

Figure 3. Invasive endometrial carcinoma extending to the cervix. 

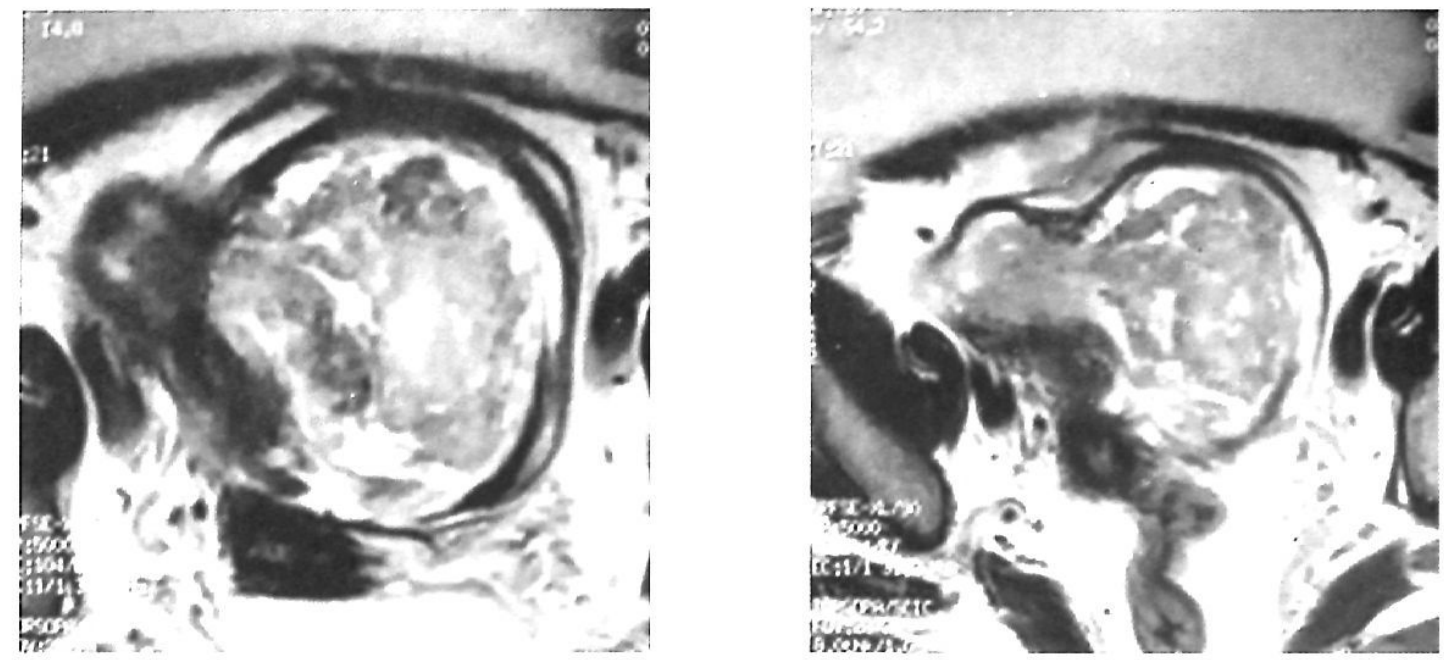

Figure 4. Uterine wall leiomyosiarcoma
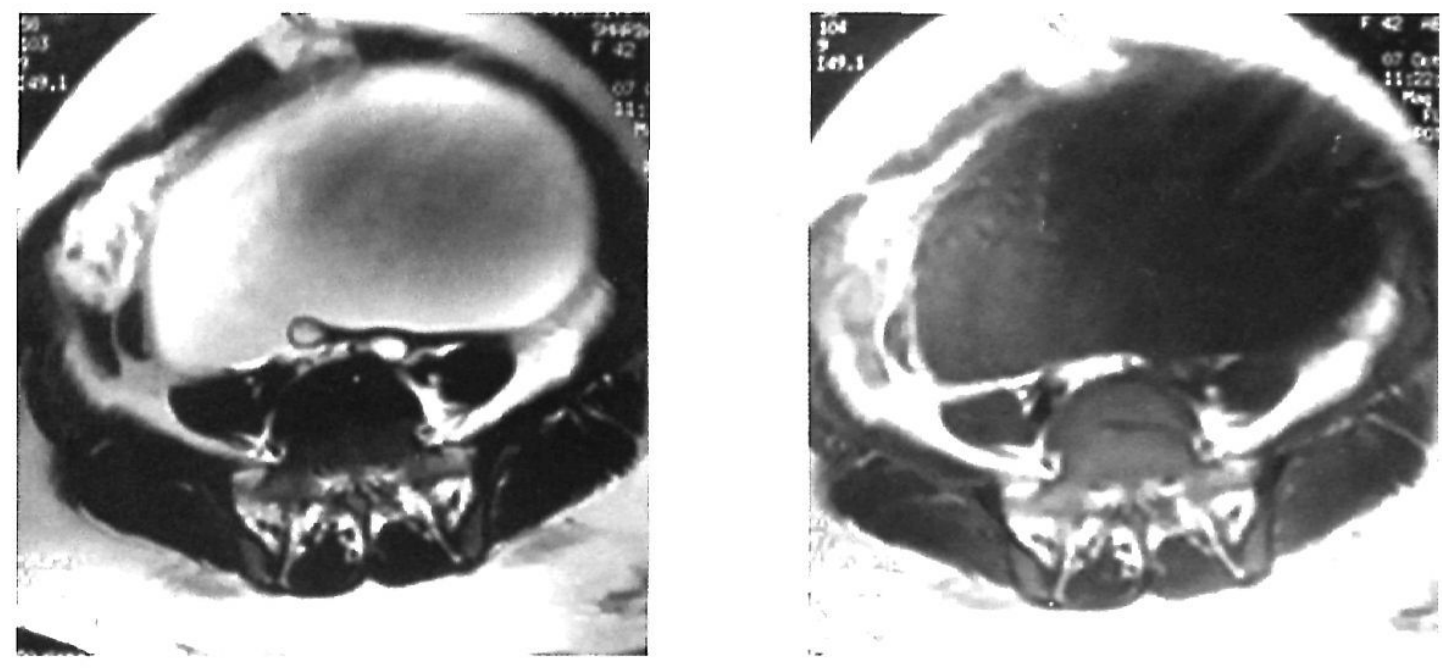

Figure 5. Ovarian serous cystadenoma
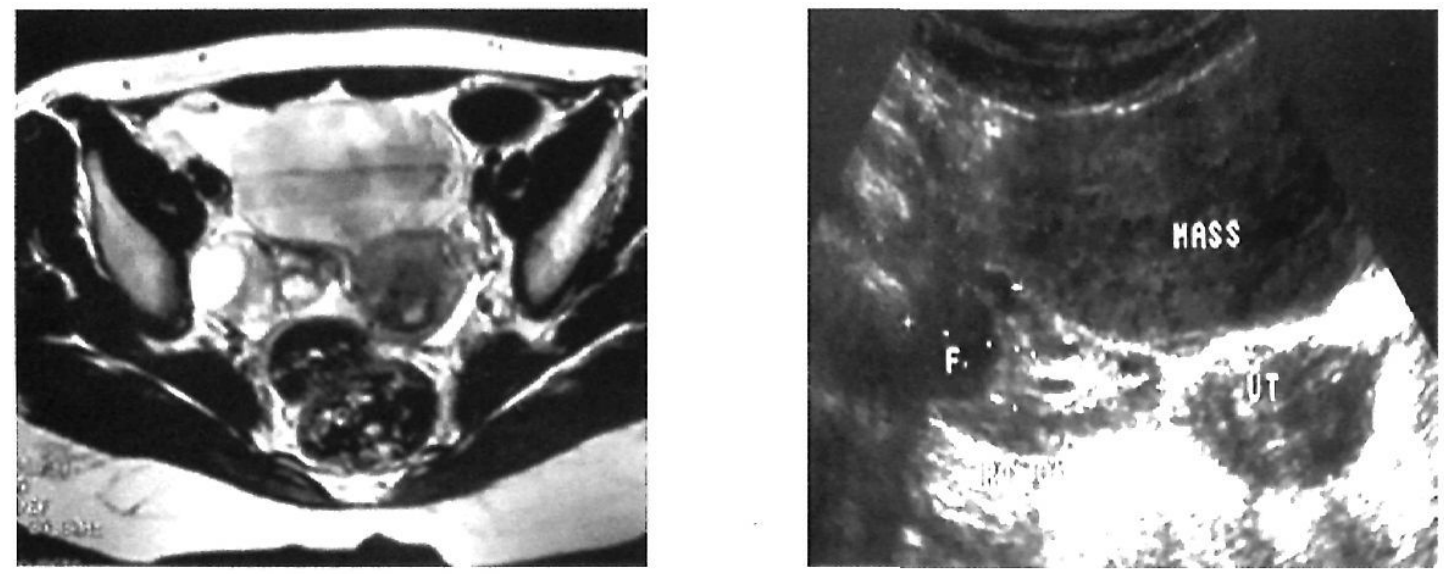

Figure 6. Ovarian torsion 
reache up to $100 \%$ in benign uterine lesions, compared with pathological examination.

There is an agreement that MRI is an ideal non-invasive technique in the assessment of normal anatomy and tissue characterization of pelvic pathology. The excellent soft-tissue contrast and the ability to direct multiplanar imaging and to demonstrate blood vessels without the use of intravenous contrast make MRI superior to other imaging modalities in the evaluation of pelvic abnormalities. The anatomical relation of the visceral organs, the differential zonal anatomy of the corpus uteri and the cyclical endometrial changes during the menstrual cycle are well depicted with $\mathrm{MRI}^{(7)}$.

Regarding the benign uterine lesions, we found 9 patients with leiomyoma and 6 patients with adenomyosis. All these cases were diagnosed by MRI, which is in agreement with Moghadam et al who found that MRI has a high specificity and more conclusive in diagnosing focal uterine adenomyoma thus differentiating between it and uterine myomas ${ }^{(9)}$.

Diffuse adenomyosis is seen on T2 weighted sequences as diffuse or segmental thickening of the low signal intensity junctional zone to greater than $12 \mathrm{~mm}^{(10)}$. Punctate foci of increased signal within the affected junctional zone are characteristic and are thought to represent nests of endometrial glands and foci of hemorrhage. Occasionally focal adenomyosis is difficult to distinguish from a leiomyoma, because both lesions are of low signal intensity on $\mathrm{T} 2$ weighted sequences. However, focal adenomyosis is ovoid in shape rather than round, has indistinct margins without a pseudocapsule, and is frequently in continuation with the Junctional zone $e^{(1)}$

Levine reported that fibroids represent the most common uterine mass, and are present in up to $25 \%$ of women older than 35 years old. The diagnosis of a fibroid uterus is typically made by ultrasound. However, at times the uterus will be enlarged and focal fibroids will not be identifiable. Fibroids typically are round, well-defined, and of low signal intensity on T1- and T2- weighted imaging. Areas of increased signal intensity on cither T1- or T2weighted images in fibroids can be due to degeneration(12)

MRI sensitivity and specificily, respectively, atre $96 \%$ and $100 \%$ for the diagnosis of subserosal leiomyomas (13). These results concur with the results of the present sludy, as wo succecded in diagnosis of 9 cases of uterine myomas by MRI (100\%), meanwhile US diagnosed only 8 cases $(88.9 \%)$.

Compared with MRI, we lound that there is a lack of specificity of US in daignosis of adenomyosis due to the similar appearance of adenomyosis and fibroids in ultrasound images. This finding is in agreement with that of other authors $(14,15)$. So, MRI is a quick and efficient way to further evaluatc ultrasonographically indeterminate pelvic masses ${ }^{(16)}$.

In the current investigation we found that endometrial carcinoma caused enlargement of the uterine lumen whercas lciomyosarcoma appeared as large intramural mass with indeterminate endometrial cavity. MR signal intensity of malignant uterine lesions in our study were low to intermediatc signal intensity in T1 \& intermediate to high signal intensily in $\mathrm{T} 2$, the'same as reported by Sicgel ${ }^{(17)}$.

Endometrial carcinoma was diagnosed in 5 of our patients, 4 of them were confined to the uterine corpus and diagnosed with excellent tissue contrast by MR. Ultrasonography diagnosed myometrial invasion in 2 cases only $(40 \%)$. MRI is significantly more valuable in the assessment of the size of the tumour, the depth of invasion, and the local-regional extent of the disease (direct invasion of the parametrium, pelvic side-wall, bladder, or rectum) $)^{(18)}$. 
Benign ovarian lesions were diagnosed in 12 patients in this study, which is consistent with Hany study ${ }^{(19)}$.

The current study included 3 patients with simple ovarian cysts that had a uniformly thin wall surrounding a single cavity that contains clear fluid and no internal echoes and displayed low signal intensity in T1 \& high signal intensity in T2; one patient presented with cystic lesion with thin wall but showed small strand like papillary projections that proved to be serous cystadenoma. A multilocular cyst with no solid parts and no hemorrhage proved to be mucinous cystadcnoma; the same criteria as described by Lu et al ${ }^{(20)}$. These results are consistent with those of Layer et al (21).

Endometriomas typically, exhibit high signal intensity on T1- weighled images and fat saturation images, the lack of reduction of signal intensity on fat saluration images is important in the distinction between endometriomas and dermoid cysts. A dingnosis of an endometrioma can be reliable if the lesion consisis of multiple high-intensily cysts on fat saturation TI-weighted images. Another reliable sign of endometriotic cysts is a cyst that exhibits high signal intensity on a Tl-weighted image and is of heterogeneous low intensity on a T2-weighted image. This pettern of signal intensity is called shading ${ }^{(22)}$.

The studied endometriotic cysts in our study showed mixed sigral intensity of the fluid content of the ovarian cysts, showed lo signal intensity mixed with intermediate signal intensity in $\mathrm{T} 1$, and showed bright signal intensity mixed with intermediate signal intensity in $\mathrm{T} 2$ weighted images, which is corresponding to blood content in different stages. These results differ from those of Togashi er al ${ }^{(22)}$.

MRI cvaluation of wo patients with dermoid cysts in our study, displayed high signal intensity in Tl weighted image consistent with fat or fresh blood with basal area of signal void consistent with calcification; in $\mathrm{T} 2$ weighted images showed Iow signal intensity with fixed basal signal void, in fat suppression sequences the contents of the cyst appeared low signal interisity and this proved that it was fat content. Rha, et al proved that mature cystic teratoma is a commonly encountered ovarian lumour, constituting $20 \%$ of all ovarian tumorus in aduls and $50 \%$ of all ovarian tumours in children. Mature cystic teratomas are composed of well-dilferentiated derivations of the three germ cell layers (ectoderm, mesoderm, and endoderm). In most cases, they are easily diagnosed on imaging studies because of their characteristic intramural fat component. Although lypical imaging findings of mature cystic teratomas are well known to radiologists, various atypical imaging features can be particularly misleading. Atypical imaging manifestations of mature ovarian cystic teratomas depending on their tumour components and the presence of combined complications on CT and MRI. Rarely, mature cystic teratomas have a pure fal component on imaging without any other component. These tumours may mimic other uncommon lipid-containing pelvic tumours such as pedunculated lipomatous uterine tumour, benign pelvic lipoma, and liposarcoma(23).

Acute abdominal pain was the leading clinical presentation of ovarian torsion. Imaging findings vary according to the stage of torsion (eg, the extent of edema and ischemia). With hemorhage and necrosis, torsion presents as a necrotic mass that lacks enhancement. At an early stage, a torsed ovary is swollen with multiple follicles separated by edematous stroma. In both stages, the common finding is the presence of a thick pedicle between the mass and the uterus ${ }^{(2)}$. Massive ovarian edema is likely to occurs with incomplete and intermittent torsion of the ovaries. MR imaging findings vary, probably reflecting different stages of this condition. Findings include masses that are not distinguishable from ovarian cancer and a prominently enlarged ovary embedded with multiple cysts ${ }^{(25)}$. 
The MRI findings of the case of ovarian torsion included in the current study showed swollen left ovary with multiple minute follicles arranged peripherally, the stroma of the ovary exhibited low signal intensity in $\mathrm{T} 1$, and high signal intensity in $\mathrm{T} 2$ weighted image denoting massive ovarian edema and this is consistent with early stage ovarian torsion as reported by Haque \& Kramer $^{(25)}$.

The imaging findings of polycystic ovaries alone are not specific, but identification of multiple peripheral cysts beneath the capsule may help in the consideration of this condition. We found a great agreement regarding $M R I$ appearance of the case of polycystic ovary in our study with that mentioned by Kimura (26).

We encountered adnexal extraovarian cysts in 2 of our studied cases. MR showed large unilocular cysts that displayed low signal intensity in T1 \& high signal intensity in $\mathrm{T} 2$ with no solid parts of septations. These findigns agree wth those of Forstner and Kinkel (27).

Regarding ovarian masses, Hricak and Stevens stated that the primary advantage of MRI in evaluation of ovarian masses is the abiltiy to characterize tissues with MRI. The presence of fat, hemorthage, mucin, fluid, and solid tissue within an ovarian mass can be determined by using MRI. The tissue characterizing ability with MRI is most useful in determining that a mass is definitely benign. to determine the potential of malignancy for epithelial tumours, assessing the internal architecture is useful. The presence of wall and septal thickness and irregularity, as well as enhancing nodules, suggests malignancy. Gadolinium enhancement is useful in this situation, for example, in differentiating solid papillary tissue (which can enhance) from clot or debris (which does not). Gadolinium enhancement is useful in evaluating the internal architecture of predominantly cystic lesions. In addition, if the mass is malignant, gadolinium enhancement may aid in depicting peritoneal implants ${ }^{(28)}$.

The accuracy of gadolinium-enhanced MRI in the diagnosis of ovarian malignancy was $93 \%$; tho findings most predictive of malignancy are necrosis in a solid lesion and vegetations in a cystic lesjon. In addition, ancillary findings on MRIs, such us ascites, peritoneal metastases, and hemorrhage, had a high predictive value for malignancy. The wse of gadolinium-based contrast agents improves tissue characterization and increases the degree of confidence with $\mathrm{MRI}^{(29)}$.

Nine palients with malignant ovarian masses were encountered in our study: 8 of them showed mixed cystic and solid components, and onc patient showed a completely solid lesion. All lesions showed various degrees of enhancement of solid parts after contritst (gadolinium chelate) administration. Necrotic and degenerations were seen in the solid part of two patients, tow lesions showed thickened wall and septae. Ancillary finding was ascites in one case. These are suggeslive of malignancy and arc consistent with the findings of Hricak and Slevens study ${ }^{(28)}$.

Togashi stated that serous and mucinous tumours are the most common surface epithelial tumours. They can vary from entirely cystic to entirely solid, but benign diagnosis should be applied only for lesions that do not have solid tissue on imaging findings; the serous cystadenoma is usually unilocular and contains fluid similar to that of simple fluid. The mucinous cystadenoma is typically multiloculated and shows a stained-glass appearance (with compartments of varying signal intensity) or daughter cysts. Thick, mucinous content that accasionally exhibits low intensity on T2- weighted images is also common in mucinous tumours. There is a close agreement between the present study and that of Togashi (22) 


\section{REFERENCES}

1. Susan M and Ascher SM. MR imaging of the female pelvis: The time has come. Radiographics 1998; 931-945.

2. Fielding JR. MR imaging of the female pelvis. Radiol Clin N Am 2003; 41: 179-192.

3. Levine D, Barnes PD, and Edelman RR. Obstetric MR imaging. Radiology 1999; 211: 609-617.

4. Brown MA and Sirlin CB. Female pelvis Genital Diseases; Magn Reson Imaging. Clin N Am J 2005; 13(2): 381-395.

5. Schwartz LB, Panageas E, Lange R, Rizzo J, Comite F, McCarthy S. Female pelvis: impact of MR imaging on treatment decisions and net cost analysis. Radiology 1994; 192: 55-60.

6. change SD, Cooperberg PL, Wong AD, Llewellyn $\mathrm{PA}$ and Bilbey JH. Limited-sequence magnetic resonance imaging in the evaluation of the ultrasonographically indeterminate pelvic mass. Can Assoc Radiol J 2004; 55: 87-95.

7. Paramasivam S, Proietto A, and Puvaneswary $M$. Pelvic anatomy and MRI Clin Obstet Gynaecol 2006; 20(1): 3-22.

8. Balan P. Ultrasonography, computed tomography and magnetic resonance imaging in the assessment of pclvic pathology. Eur J Radiol 2006; 58(1): 147-155.

9. Moghadam R, Lathi RB, Shahmohamady B, Saberi NS, Nezhat $\mathrm{CH}$, Nezhat $\mathrm{F}$ and Nezhat C. Predictive value of magnetic resonance imaging in differentiating between leiomyoma and adenomyosis. JSLS 2006; 10(2): 216-219.

10. Leving D. Solving the Problem Pelvic Ultrasound with Magnetic Resonance Imaging. Ultrasound Quarterly, Volume 22, Number 3, September 2006.

11. Reinhold C, McCarthy S, Bret PM, Mehio A, atri M, Zakarian R, Glaude Y, Liang L and Seymour RJ. Prospective comparative analysis of endovaginal $\mathrm{U} / \mathrm{S}$ and MRI with histopathologic correlation. Radiology 1996; 199: 151-158.

12. Togashi $K$, Ozasa $H$, Konishi I, Itoh $H$, Nishimura K, Fujisawa I, Noam S, Sagoh T, Minami S and Yamashita $\mathrm{K}$. Enlarged uterus: Differentiationbetween adenomyosis and leiomyoma with MRI. Radiology 1989, 171: $531-534$

13. Scoutt LM, McCarthy SM, Lange R, Bourque A, Schwartz PE. MR evaluation of clinically suspected adenexal masses. J Comput Assist Tomogr 1994; 18: 609-618.

14. Tanaka YO, Yoshizako T, Nishida M, Yamaguchi $M$, Sugimura $K$, Itai $Y$. Ovarian carcinoma in patients with endometriosis: MR imaging findings. AJR 2000; 175: 1423-1430.
15. Outwater EK, Siegelman ES, Van Deerlin V. Adenomyosis: current concepts and imaging considerations. AJR 1998; 170: 437-441.

16. Kim IC, Kim SS, and Park JY. Bridging vascular sign in the MR diagnosis of exophytic uterine leiomyoma. J Comput Assist Tomogr 2000; 24(1): 57-60.

17. Siegel MJ. Female pelvis. In: Siegel MJ, (ed). Pediatric sonography. 3rd edition. Philadelphia: Lippincott Williams \& Wilkins 2002; 528-577.

18. Nicolet V, Carignan L, Bourdon F, Prosmanne O. MR imaging of cervical carcinoma: a practical staging approach. Radiographics 2000; 20(6): 1539-1549.

19. Hany A.A.: Imaging modalities in adnexal masses, Thesis submitted for partial fulfillment of the master degree in Radiodiagnosis, Mansoura University, 1998.

20. Lu D, Davila RM, Pinto KR, Lu DW. Thinprep evaluation of the fluid samples aspirated from he cystic ovarian masses. Diagn Cytopathol 2004; 30: 320-324.

21. Loyer EM, Whitman GJ, and Fenstermacher MJ. Imaging of ovarian carcinoma. Int J Gynecol Cancer 1999; 9(5): 351-361.

22. Togashi $K$. Imaging of the ovaries: normal appearance and benign disease. Radiol Clin N Am 2003; 41: 799-811.

23. Rha SE, Byun JY, Jung SE, Kiml HL, Oh SN, Kim $\mathrm{H}$, Lee H, Kim BK and Lee JM. Atypical CT and MRI Manifestations of Mature Ovarian Cystic Teratomas. American Jounal of Roentgenology $2004 ; 743-750$.

24. albayrak R, Degirmence B, Sahin FK and Koken G. The reversible and irreversible ischemic changes of MRI findings in torsion of normal adnexa. Kocatepe Tip Dergisi 2005; 6(3): 61.

25. Kramer LA, Lalani $T$, an Kawashima A. Massive edema of the ovary: high resoultion MR findings using a phased-array pelvic coil. J Magn. Reson. Imaging 1997; 7: 758-760.

26. Kimural , Togashi K, Kawakami S, Nakano Y, takakura K, Mori T, Konishi J. Polycystic ovaries: implications of diagnosis with MR imaging. Radiology 1996: 201: 549-52.

27. Forstner $\mathrm{R}$ and Kinkel K.; Adnexal masses: Characterization of benign ovarian lesions in: Hamm \& R. Forstner (eds): MRI and CT of the female pelvis 2007; p 197-231.

28. Hricak H, Chen M, Coakley FV, Kinkel K, Yu KK, Sica G, Bacchetti P, and Powell CB. Complex Adnexal Masses: Detection and Characterization with MR Imaging-Multivariate Analysis 1. Radiology, January 1, 2000; 214(1): 39-46.

29. Jeong YY, Outwater EK, and Kang HK. Imaging evaluation of ovarian masses. Radiographics 2000; $20(50,1445-1270$. 